\title{
Ceratoplastia com enxerto autógeno lamelar livre de córnea e pediculado de conjuntiva fixados com adesivo de cianoacrilato em cães
}

\author{
Lamellar keratoplasty produced by free corneal autograft and conjuntival pedicle fixed with \\ cyanoacrylate adhesive in dogs
}

\author{
Fabrício de Vargas Arigony Braga ${ }^{1}$ Ney Luis Pippi ${ }^{2}$ Kleber Gomes ${ }^{3}$ \\ Marcelo Weiss $^{4}$ Fabíola Flores $^{5}$ Fabíola Dalmolin $^{3}$ Douglas Severo ${ }^{6}$ \\ Luciene Krauspenhar ${ }^{7}$ Alessandro Leotte ${ }^{7}$
}

\section{RESUMO}

A córnea, devido a sua localização externa $e$ exposta, está freqüentemente sujeita a traumas ou processos lesivos como lacerações, perfurações e ulcerações, havendo, em muitos casos a necessidade de correção cirúrgica. Os enxertos pediculados de conjuntiva têm seu uso indicado nestes casos $e$ se prestam bem como medidas de proteção e suporte para as ulcerações, porém impedem a capacidade visual plena do olho afetado. Os transplantes lamelares são outra indicação de tratamento, principalmente quando se deseja prevenir a ocorrência da perda visual. Os adesivos de cianoacrilato foram descobertos no final da década de 40, mas somente foram utilizados em oftalmologia no início da década de 60. Devido a propriedades como boa aderência aos tecidos biológicos, rápida secagem e polimerização, têm sido indicados no tratamento de úlceras profundas ou refratárias, descemetoceles e ainda em pequenas perfurações corneanas. Com o objetivo de testar o adesivo de cianoacrilato na fixação e manutenção de botões córneo-lamelares autógenos e de enxertos pediculados de conjuntiva em úlceras corneanas experimentais, foram utilizados 10 cães, machos ou fêmeas, provenientes do Biotério Central da Universidade Federal de Santa Maria (UFSM). Após anestesia, blefarostase e fixação do globo ocular como de rotina, foram realizadas trepanações compreendendo $2 / 3$ da espessura da córnea sendo de 5,5mm de diâmetro no olho esquerdo $(O E)$ e de $5 \mathrm{~mm}$ no olho direito $(O D)$. O botão lamelar resultante do $O E$ foi fixado no leito receptor do OD com o uso de adesivo ao longo das bordas do enxerto e da córnea receptora. No olho esquerdo, após sua confecção, o enxerto de conjuntiva pediculado foi fixado à área receptora também por meio da colocação de adesivo sobre suas bordas. Foi realizada avaliação oftalmológica diária durante 30 dias. Os botões lamelares permaneceram fixados $e$ foram incorporados à córnea receptora. A técnica de fixação foi de fácil realização, sendo rápida e de baixo custo com opacidade leve em $20 \%$ dos casos e ausente em $80 \%$ e ausência de vascularização aos 30 dias. Porém, houve 100\% de deiscência total nos enxertos pediculados. A técnica de ceratoplastia lamelar autógena com o uso de adesivo de n-butil cianoacrilato pode ser indicada como opção terapêutica nas úlceras profundas em cães.

Palavras-chave: úlcera, transplante, cola, cirurgia.

\section{ABSTRACT}

The cornea is frequently exposed to traumas, lacerations, perfurations and ulcers, needing in most cases surgical correction. The conjunctival pedicle grafts are indicated in these cases, giving protection and support for ulcers, but obstructing the visual capacity of the affected eye. The lamelar grafts are other indications for treatment, mainly when preventing the visual loss. The cianoacrylate adhesive was discovered at the end of the forthies, but started to be used in ophtalmology in the begigning of the sixties. Due to its properties, as good tissue adhesion, quick dried and polimerization, it has been indicated in the treatment of deep or refractive corneal ulcers, descemetoceles and in punctiform corneal perforations. With the objective to test the cianoacrylate adhesive in the fixation and maintenance of corneolamelar grafts and conjunctival pedicle grafts in corneal ulcer, 10 male and female mongrel dogs from the Central Bioterio of Santa Maria Federal University were used. After anesthesia protocol and routine eyeball fixation, a

\footnotetext{
${ }^{1}$ Médico Veterinário, Mestre, Doutorando, Programa de Pós-graduação em Medicina Veterinária (PPGMV), Laboratório de Cirurgia Experimental (LACE), Universidade Federal de Santa Maria (UFSM). E-mail:bragafa@ hotmail.com. Autor para correspondência.

${ }^{2}$ Médico Veterinário, PhD, Professor Adjunto, Departamento de Clínica de Pequenos Animais, UFSM.

${ }^{3}$ Médico Veterinário, mestrando do PPGMV, LACE, UFSM.

${ }^{4}$ Acadêmico do Curso de Medicina Veterinária, UFSM. Bolsista do CNPq.

${ }^{5}$ Médico Veterinário, Mestrando em Anestesiologia, Universidade do Estado de Santa Catarina, Lages, SC.

${ }^{6}$ Médico Veterinário, Mestre, Doutorando PPGMV, LACE, UFSM.

${ }^{7}$ Médico Veterinário, Mestre, Autônomo.
} 
trephination was performed, involving 2/3 of the corneal stroma, being $5.5 \mathrm{~mm}$ in diameter in the left eye and $5 \mathrm{~mm}$ in the right eyes. The lamelar corneal grafts from the left eyes were fixed in the recipient cornea of the right eyes, using the adhesive in the margin of the graft. In the left eyes, a conjunctival pedicle flaps were fixed in the corneal deffects, using the same adhesive in the margins. Daily ophtalmologic control was made during 30 days. The corneal lamelar grafts were incorporated to the recipient cornea. The fixation technique was rapid and easily performed, with low cost. The eyes had $20 \%$ opacities with the use of the lamelar corneal graft, and $80 \%$ with no vascularization and opacities present in 30 days. When conjunctival flaps technique was used, it has 100\% dehiscence of the cases.

Key words: ulcer, transplant, glue, surgery.

\section{INTRODUÇÃO}

A úlcera de córnea é uma das doenças oculares mais comuns em cães, levando freqüentemente à perda da visão (NASSISE, 1985). A terapia medicamentosa é recomendada isolada ou concomitante a procedimentos cirúrgicos em ulcerações superficiais e profundas nos quais o principal objetivo é o suporte mecânico e o cessamento da destruição corneana (SEVERIN, 1976; SLATTER \& HAKANSON, 1998).

Os enxertos conjuntivais pediculados são citados por muitos autores como procedimentos de eleição em ulcerações profundas ou progressivas (HAKANSON \& MERIDETH, 1987; HAKANSON et al., 1988; HABIN, 1995) sendo considerados de fácil realização em relação a outros procedimentos (LAUS et al., 1996; MARCHIONATTI, 1998). Suas vantagens são principalmente a possibilidade de as estruturas oculares ao redor do defeito poderem ser inspecionadas e o estabelecimento de aporte vascular de substâncias com efeito cicatrizante e inibidor da colagenase (NASISSE, 1985; HABIN, 1995), entretanto, o uso desta técnica freqüentemente está relacionado com a perda da visão no local onde são fixados (HAKANSON \& MERIDETH, 1987).

Já as ceratoplastias lamelares, com seu uso corriqueiro em medicina humana (ACEDO, 1992), exibem na medicina veterinária algumas dificuldades como a necessidade de material especializado e, quando homólogas, demandam o uso de medicações imunossupressoras e necessitam de doadores (SLATTER \& HAKANSON, 1998). BRIGHTMAN et al. (1989) afirmaram que o uso de córnea autógena sobrepõe estes últimos obstáculos. BERNIS, em 1980, recomendou esta técnica para o tratamento de algumas ceratopatias que impeçam parcial ou totalmente a visão como nas ceratectomias profundas com tendência à opacificação pós-operatória (COOK \&
PEIFFER, 1985). WILKIE \& WHITTAKER (1997) acrescentaram como indicações, o reparo de úlceras não perfuradas ou pequenas perfurações, as degenerações corneanas e a restauração da espessura estromal.

Desenvolvidos inicialmente no final da década de 40 (OLLIVIER et al., 2001), somente em 1963 os adesivos de cianoacrilato tiveram seu primeiro uso em oftalmologia (ELLIS \& LEVINE, 1963). Estas substâncias são compostos líquidos, transparentes, com alguma atividade antimicrobiana (AWE et al., 1963; EIFERMAN \& SNYDER, 1983; QUINN et al., 1995) que quando em contato com superfícies úmidas polimerizam em alguns segundos, estabelecendo o processo adesivo (GASSET et al., 1970; PAPATHEOFANIS \& BARMADA, 1993) e tornando alguns procedimentos significativamente mais rápidos (QUINN et al., 1997; TORIUMI et al., 1998; PELISSIER et al., 2001). Apresentam graus variados de histotoxicidade de acordo com o número de carbonos presentes em sua fórmula (quanto mais carbonos, menor a toxicidade) e com a quantidade de adesivo dispensada para o procedimento (ELLIS \& LEVINE, 1963; REFOJO et al., 1968; ARONSON et al., 1970; GARRIDO et al., 1999).

Outros adesivos já foram testados em oftalmologia como o adesivo de fibrina (VALERO et al., 2001) e de silicone (REFOJO et al., 1968). ROSENTHAL et al. (1975) usaram um composto de plaquetas, fibrinogênio e trombina para a fixação de enxertos lamelares corneanos em coelhos obtendo $50 \%$ de sucesso aos 21 dias de avaliação. Em uma série de 49 ceratoplastias lamelares autógenas e homógenas utilizando o cianoacrilato, CARDARELLI \& BASU (1969) consideraram apenas 10 procedimentos como bem sucedidos, porém observaram opacidade moderada em todos.

Em oftalmologia veterinária, os cianoacrilatos não têm seu uso bem estabelecido, tendo sido indicados para alguns procedimentos como tratamento de ulcerações corneanas refratárias (BROMBERG, 2002), tratamento de pequenas descemetoceles ou pequenas perfurações corneanas (WILKIE \& WHITTAKER, 1997).

O presente trabalho teve como objetivos avaliar o uso de um adesivo à base de n-butil cianoacrilato (Vetbond ${ }^{\circledR}$ ) na fixação e manutenção de botões córneolamelares autógenos e de enxertos pediculados de conjuntiva bulbar em úlceras corneanas iatrogênicas não infectadas e avaliar a técnica utilizada para a realização destes procedimentos. 


\section{MATERIAL E MÉTODOS}

Foram utilizados 10 animais, sendo sete fêmeas e três machos, adultos, com pesos variando entre 8 e $15 \mathrm{~kg}$, provenientes do Biotério Central da Universidade Federal de Santa Maria. Após exame clínico e oftálmico constituído pelo teste lacrimal de Schirmer, oftalmoscopia direta e indireta, tonometria por aplanação e fluoresceína, com vistas a verificar e excluir animais portadores de qualquer alteração que pudesse interferir com os resultados, foram acondicionados em baias com ração e água ad libitum.

Previamente ao procedimento cirúrgico, os animais foram banhados e submetidos à restrição hídrica e alimentar de 12 horas. O protocolo anestésico foi constituído de pré-medicação com uma associação de citrato de fentanila ${ }^{\mathrm{a}}\left(0,002 \mathrm{mg} \cdot \mathrm{kg}^{-1}\right)$ e acepromazina ${ }^{\mathrm{b}}$ $\left(0,05 \mathrm{mg} . \mathrm{kg}^{-1}\right)$ administrada por via intra-muscular, indução anestésica com tiopental sódico ${ }^{c}$ na dose de $12,5 \mathrm{mg} \cdot \mathrm{kg}^{-1}$ por via intra-venosa, intubação e manutenção dos animais em plano cirúrgico com halotano $^{\mathrm{d}}$ vaporizado com oxigênio em sistema semifechado. Foram instiladas duas gotas de colírio anestésico $^{\mathrm{e}}$ em cada olho e realizado o bloqueio retrobulbar utilizando-se $0,5 \mathrm{ml}$ de cloridrato de lidocaína $^{\mathrm{f}}$ a $1 \%$ associado a $0,5 \mathrm{ml}$ de cloridrato de bupivacaína $^{\mathrm{g}}$ a $0,5 \%$ na mesma seringa. A profilaxia antimicrobiana foi constituída de ampilicina sódica ${ }^{\mathrm{h}}$ IV na dose de $20 \mathrm{mg} \cdot \mathrm{kg}^{-1} 30$ minutos antes da intervenção cirúrgica.

Após os procedimentos de anti-sepsia com PVPI diluído a $1 \%$ em solução fisiológica a $0,9 \%$ estéril e delimitação do campo operatório, foi realizada a blefarostase e fixação do globo ocular esquerdo com o auxílio de duas pinças de Halsted curvas aplicadas à conjuntiva bulbar nas posições de $10 \mathrm{e} 4$ horas.

Com vistas a obtenção de um botão lamelar e da realização de úlceras experimentais, um trépano de Castroviejo de 5,5mm foi aplicado de forma penetrante, delimitando o botão constituído de epitélio e aproximadamente $2 / 3$ do estroma, excisado com auxílio de uma lâmina de bisturi $\mathrm{n}^{\circ} 15$ e mantido em uma gaze umedecida em solução fisiológica. Ato contínuo, foi confeccionado um enxerto conjuntival bulbar pediculado. A técnica teve início com uma incisão na conjuntiva bulbar dorsolateral, perpendicular ao limbo, com tamanho relativo ao do defeito receptor. A posição desta incisão foi aproximadamente em 3 horas, para que o pedículo pudesse alcançar o defeito sem estar sob tensão. Uma segunda incisão, paralimbal, foi realizada iniciando na extremidade proximal da incisão perpendicular e distando em torno de $2 \mathrm{~mm}$ do limbo até 12 horas. Uma terceira foi realizada na outra extremidade da incisão perpendicular sendo também paralimbal e estendida até 12 horas, sendo levemente mais curta que a anterior, com o objetivo de se preservar a largura da base do pedículo e não prejudicar a vascularização do mesmo. A dissecção final da conjuntiva foi feita com tesoura de íris e uma pinça de Castroviejo mantendose o pedículo o mais delgado possível, rotando-o finalmente, até o local da lesão. A sua extremidade distal foi modelada com auxílio de tesoura de íris para se adaptar ao defeito corneano previamente realizado. Aproximadamente $0,05 \mathrm{ml}$ de adesivo de n-butil cianoacrilato (Vetbond ${ }^{\circledR}$ ) foi aspirado em uma seringa de insulina que foi acoplada a uma agulha $\mathrm{n}^{\circ} 27 \mathrm{G}$ angulada em $45^{\circ}$ e sem a extremidade biselada. $\mathrm{O}$ enxerto conjuntival foi colocado sobre o leito receptor, quando se aplicou quantidade mínima necessária de adesivo, distribuindo-o com a agulha angulada para cobrir em torno de $2 \mathrm{~mm}$ das bordas do enxerto e do defeito (Figura 1a).

Utilizando-se os métodos de blefarostase e fixação do globo ocular descritos anteriormente, procedimento semelhante de produção da úlcera foi realizado no olho contra-lateral, somente utilizandose um trépano de Castroviejo de $5 \mathrm{~mm}$. Sobre a janela resultante, foi colocado o botão lamelar coletado anteriormente. Neste caso, o adesivo foi aplicado sobre as bordas em coaptação, abrangendo um segmento da córnea receptora e também do enxerto, permitindo assim, sua fixação. À semelhança do descrito anteriormente, o adesivo foi distribuído para que se formasse uma camada fina sobre as bordas (Figura 1b). Tanto no olho direito quanto no esquerdo, prévio à aplicação do adesivo, a córnea foi seca com auxílio de cotonetes estéreis.

Como terapia analgésica, Flunixim meglumine $e^{\mathrm{j}}$ na dose de $1 \mathrm{mg} \mathrm{kg}^{-1}$ foi administrado por via subcutânea no pós-operatório (PO) imediato e nos dois dias subseqüentes à cirurgia. Como medida profilática à infecção e ao espasmo ciliar, foi feita a aplicação de pomada oftálmica antibiótica ${ }^{k}$ e atropina $1 \%$, respectivamente, com intervalo de 12 horas em ambos os olhos até a verificação da reepitelização pelo teste de fluoresceína quando estes medicamentos foram trocados por uma associação de antibiótico e corticosteróide ${ }^{\mathrm{m}}$ administrada na mesma frequiência. Os animais foram mantidos com colar protetor durante todo o curso do experimento.

Com auxílio de uma lupa e de uma lanterna, o protocolo de avaliação oftalmológica consistiu na realização do teste de fluoresceína diariamente até a ausência de coloração, observando-se a presença do adesivo e a reepitelização corneana. Também foram 
avaliadas as reações de fotofobia, blefarospasmo, edema, transparência, neovascularização, uveíte e secreção ocular (serosa, sero-mucosa, mucosa, purulenta), quantificando-as segundo um padrão em que: $0=$ ausente, $+=$ leve,$++=$ moderada e $+++=$ severa. Aos 7, 14, 21 e 30 dias de PO, foram feitas avaliações ao microscópio cirúrgico em aumentos de 16 e 40x. O animal foi sedado com uma associação de citrato de fentanila e acepromazina nas doses e vias citadas anteriormente e foram instiladas duas gotas de colírio anestésico no saco conjuntival para facilitar o exame. Ao final do período de avaliação, os animais foram encaminhados ao serviço de adoção do Hospital Veterinário da UFSM.

\section{RESULTADOS E DISCUSSÃO}

$\mathrm{O}$ adesivo Vetbond ${ }^{\circledR}$ é um adesivo a base de n-butil cianoacrilato comercializado para uso em Medicina Veterinária. Em oftalmologia já foi testado de forma intralamelar e como tratamento de úlceras experimentais em córneas de coelhos obtendo-se bons resultados quanto a sua biocompatibilidade (OLLIVIER et al., 2001), o que despertou interesse para seu uso neste experimento.

A indicação de diversos procedimentos cirúrgicos para o tratamento de úlceras corneanas é justificada pelas particularidades de cada uma destas técnicas, e pelas particularidades das próprias úlceras quanto à sua causa e estágio de progressão. Diversos autores citam os procedimentos de ceratoplastia lamelar e enxerto conjuntival pediculado como alternativas passíveis de serem executadas, descrevendo também suas indicações (SEVERIN, 1976; BERNIS, 1980; COOK \& PEIFFER, 1985; HAKANSON \& MERIDETH, 1987; HABIN, 1995; WILKIE \& WHITTAKER, 1997)

Para a realização dos procedimentos cirúrgicos, os animais foram mantidos sob anestesia geral inalatória como utilizado por LAUS et al. (1996) e nenhuma intercorrência anestésica foi observada.

O uso de colírio anestésico objetivou a suplementação do protocolo anestésico, melhorando a desensibilização da córnea e conjuntiva aos procedimentos cirúrgicos, à semelhança de OLLIVIER et al. (2001) e BROMBERG (2002). Ainda, o bloqueio retrobulbar permitiu a centralização do globo ocular em todos os animais operados, o que facilitou os procedimentos operatórios, conforme citado por SKARDA (1996). WILKIE \& WHITTAKER (1997) recomendaram o uso de bloqueadores neuromusculares para que esta condição fosse atingida; porém, o uso destes fármacos demanda suporte ventilatório manual ou mecânico, não necessário com a técnica utilizada. Outra vantagem verificada foi a promoção de um retorno anestésico mais tranqüilo por evitar a dor no período de recuperação imediata. SKARDA (1996) citou alguns acidentes que este tipo de técnica pode ocasionar como injeção subaracnóidea, injeção intravascular e absorção sistêmica do anestésico local, que não foram verificados.

Os procedimentos de posicionamento, antisepsia, proteção do campo operatório, blefarostase, fixação do globo ocular e uso de instrumentos de magnificação foram realizados a exemplo de procedimentos oftálmicos realizados por outros autores (HAKANSON \& MERIDETH, 1987; HABIN, 1995; MARCHIONATTI, 1998; OLLIVIER et al., 2001).

SEVERIN (1976) e NASISSE (1985) comentaram que defeitos corneanos de até $5 \mathrm{~mm}$ de diâmetro podem ter, em muitos casos, a sutura direta como sua opção de tratamento, motivo pelo qual foram realizadas trepanações de 5 e $5,5 \mathrm{~mm}$. Além disto, SLATTER \& HAKANSON (1998) e ACEDO (1992) indicaram que o botão lamelar doador seja $0,5 \mathrm{~mm}$ maior em diâmetro que a janela receptora, para que ocorra maior aposição das bordas, sobrepondo assim, a retração inerente a córnea quando da sua obtenção. O seguimento desta premissa permitiu que, nas ceratoplastias, o adesivo liberado ao longo da união enxerto-receptor não ficasse depositado entre e sim, sobre as bordas. Segundo CARDARELLI \& BASU (1969) os adesivos de cianoacrilato inibem a progressão epitelial e fibroblástica; VALERO et al. (2001) afirmaram que esta inibição não é significativa clinicamente, porém, aqueles autores verificaram em seus transplantes, que em todos os casos falhos houve interposição do adesivo entre as bordas, atuando como uma barreira impermeável. No presente experimento, em três animais, houve a interposição do adesivo em mínimo grau, mas ainda atuando como estímulo para neovascularização, blefarospasmo e, à semelhança dos autores citados, impedindo a união das bordas receptora e doadora enquanto presente. Quando esta pequena quantidade foi retirada aos 21 dias, sob magnificação do microscópio cirúrgico (Figura 1c), foram permitidos a reepitelização, o desaparecimento do blefarospasmo e o cessamento da progressão dos vasos formados, em 24 a 48 horas. Segundo OLLIVIER et al. (2001) e BROMBERG (2002), o blefarospasmo resolve-se em 48 a 72 horas devido ao aplainamento da superfície rugosa da camada adesiva, o que foi verificado pela 
diminuição dos sinais entre o primeiro e o quinto dia de PO no restante dos animais operados.

Muitos são os autores que afirmaram ser a maior resposta inflamatória incitada pelo adesivo, em grande parte, relacionada com a quantidade usada deste composto (ELLIS \& LEVINE, 1963; REFOJO et al., 1968; ARONSON et al., 1970; GARRIDO et al., 1999). Procurou-se, assim, utilizar a gota distribuída sobre as bordas tanto nos enxertos conjuntivais quanto lamelares para minimizar essta complicação. Nas ceratoplastias lamelares, a agulha angulada foi usada para esta manobra, permitindo maior controle no direcionamento da gota dispendida, visto que esta é de baixa viscosidade sendo facilmente dispersada sobre a córnea (ELLIS \& LEVINE, 1963).

A opacidade foi ausente em tempos variáveis de 2 a 21 dias de PO em oito cães (Figura 1d). Apenas dois animais ainda apresentavam opacidade de grau leve aos 30 dias. BERNIS (1980) obteve transparência total somente aos 60 dias de pósoperatório em transplantes lamelares homólogos e BRIGHTMAN et al. (1989) comentaram que até os 60 dias, nenhum transplante autógeno foi transparente como a córnea receptora, existindo, ainda, cicatrizes no local da sutura e margens do enxerto.

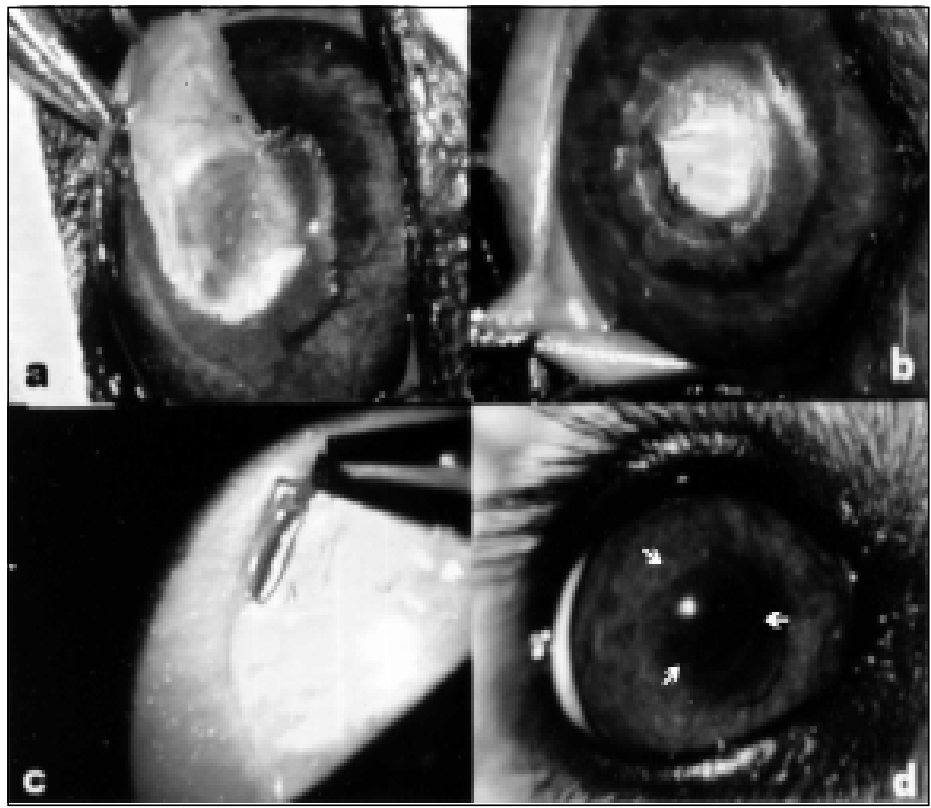

Figura 1 - a) enxerto pediculado de conjuntiva fixado com adesivo de cianoacrilato - OE b) enxerto autógeno lamelar livre de córnea fixado com adesivo de cianoacrilato - OD c) retirada de segmento de adesivo interposto às bordas na ceratoplastia lamelar aos 21 dias sob aumento de 40X; notar a falha na união entre as bordas d) enxerto autógeno lamelar livre de córnea observado aos 21 dias de pós-operatório; notar o halo ao redor do enxerto livre de córnea (setas).
No que se refere ao tipo e quantificação das secreções observadas, a serosa foi evidenciada até o quarto dia sendo compatível com os achados em perdas de continuidade epitelial corneana (NASISSE, 1985), estando presente até os 21 dias em um cão apresentando maior quantidade de adesivo interposto entre as bordas (cerca de $1 / 4$ do halo do enxerto).

Ao contrário dos pobres resultados obtidos por CARDARELLI \& BASU (1969) e ROSENTHAL et al. (1975), 100\% dos enxertos lamelares foram incorporados ao leito receptor. O tipo de adesivo e a técnica utilizada pode ter sido fator determinante para o contraste entre os resultados.

Nenhum cão apresentou sinais de processo infeccioso ocular; este achado pode ser justificado tanto pela profilaxia antimicrobiana pré-operatória, realizada segundo as indicações de RAISER (1995), quanto pelo uso de pomada oftálmica à base de antibiótico durante o pósoperatório. Também, o cianoacrilato, como citado por EIFERMAN \& SNYDER (1983), possui propriedades bacteriostáticas devidas à reação de ligações ativas da molécula de cianoacrilato com a parede celular de bactérias Gram +. Segundo este autor, isto não acontece com bactérias Gram provavelmente pela existência de uma cápsula lipopolissacarídica externa à sua parede celular que pode atuar como uma barreira às ligações do cianoacrilato. Na série de 49 transplantes realizados por CARDARELLI \& BASU (1969), não foi utilizado antibiótico pósoperatório verificando-se apenas um caso de infecção; o autor justificou este resultado pela presença do cianoacrilato. Alguns autores ainda consideram o adesivo de cianoacrilato como autoesterilizante (AWE et al., 1963). QUINN et al. (1995) submeteram a testes algumas amostras de um adesivo de cianoacrilato utilizado na rotina clínica de diferentes hospitais, para verificar a presença de contaminação após a abertura e utilização do conteúdo dos frascos; os autores não verificaram resultados positivos. Nesta pesquisa, como as quantidades dispensadas em cada procedimento não excederam 
$0,1 \mathrm{ml}$, não foi necessário o descarte do restante do conteúdo do frasco de $10 \mathrm{ml}$, tornando o procedimento de menor custo.

Em todos os 10 olhos em que foi realizado o enxerto pediculado de conjuntiva bulbar, houve deiscência total nos períodos entre 2 a 8 dias de pósoperatório com a reepitelização do leito resultante que ocorreu em 12 a 21 dias e foram verificadas áreas de opacidade variável nos defeitos. ELLIS \& LEVINE, em 1963, confeccionaram retalhos conjuntivais fixados com adesivo de cianoacrilato cobrindo metade da córnea e REFOJO et al., em 1968 transpuseram diversos tipos de enxertos conjuntivais pediculados sobre a córnea desnuda de seu epitélio fixando-os também com adesivo; estes autores observaram que, invariavelmente, alguns dias após os procedimentos, ocorria o rompimento do filme adesivo com conseqüente deiscência dos pedículos devido a sua retração.

Segundo HAKANSON \& MERIDETH (1987) e HAKANSON et al. (1988), as principais causas de deiscência dos enxertos conjuntivais pediculados são: desbridamento corneano incompleto, vazamento de humor aquoso, excessiva tensão e angulação do pedículo maior que $45^{\circ}$ em relação ao eixo vertical. Neste experimento, em nenhum caso houve a perfuração da câmara anterior e os pedículos foram confeccionados de forma padrão com zero grau de inclinação em relação à posição de 12 horas. $\mathrm{O}$ defeito conjuntival resultante da dissecção do pedículo não foi suturado por não apresentar sangramento evidente, à semelhança de LAUS et al. (1996) e MARCHIONATTI (1998). HAKANSON \& MERIDETH (1987) esclareceram que talvez não fosse necessária esta sutura, mas a recomendaram para que ocorra a estabilização da base do pedículo e melhor cicatrização conjuntival. A retração inerente à cicatrização por segunda intenção deste defeito, aliada à retração do próprio pedículo, pode ter contribuído para o estabelecimento de tensão no pedículo conjuntival que sobrepôs a força de adesão do cianoacrilato favorecendo a deiscência total; além disto, o fato de o adesivo ter sido distribuído sobre as bordas para que a presença de um filme adesivo mais fino e com menor quantidade do produto evitasse maior reação, pode ter contribuído para a insuficiente adesão por haver mobilidade da conjuntiva durante este procedimento.

HAKANSON \& MERIDETH (1987) estabeleceram que o epitélio deve ser removido 0,5 a $1 \mathrm{~mm}$ ao redor da úlcera para permitir a adesão da conjuntiva na técnica convencional e WILKIE \& WHITTAKER (1997) afirmaram que os adesivos teciduais não aderem bem ao epitélio corneano sugerindo sua remoção prévia à aplicação do cianoacrilato. Optou-se por não realizar este procedimento para testar a capacidade adesiva sobre o epitélio e para que o procedimento fosse de mais fácil realização, o que pode ter contribuído, também, para a deiscência dos enxertos.

PAPATHEOFANIS \& BARMADA (1993)

definiram, como uma etapa vital na aplicação do adesivo, a utilização de técnicas que permitam a apresentação de superfícies adequadamente secas e livres de contaminantes como o sangue, pois a água difunde-se entre o adesivo e as camadas aderentes rompendo sua junção, bem como a presença de lipídios ou óleos diminuem acentuadamente a capacidade de adesão. Neste experimento, a utilização de cotonetes esterilizados, à semelhança de REFOJO et al. (1968) e diferentemente de OLLIVIER et al. (2001) que usaram esponjas de celulose, foi considerada fácil e eficaz na preparação da córnea e conjuntiva. Deve-se lembrar que a fricção sobre estas estruturas deve ser mínima com o intento de se preservar as camadas epiteliais superficiais.

O tempo médio de aplicação e polimerização do adesivo para os enxertos conjuntivais foi de 4 minutos e 27 segundos e de 2 minutos e 36 segundos para os botões lamelares. Não houve comparação entre o tempo de aplicação do adesivo e de fixação dos enxertos por sutura. Porém, existem diversos trabalhos demonstrando que a realização dos procedimentos de síntese tecidual com o uso de adesivos é significativamente mais rápida do que com o uso de suturas (QUINN et al., 1997; TORIUMI et al., 1998; PELISSIER et al., 2001). Este fato é importante do ponto de vista econômico, pela menor demanda de anestésicos e de segurança do paciente que será submetido a menor estresse anestésico.

A avaliação à luz da microscopia ótica tornou-se desnecessária no tocante à reação da córnea ao adesivo por existirem exaustivas pesquisas neste tópico (ELLIS \& LEVINE, 1963; REFOJO et al., 1968; CARDARELLI \& BASU, 1969; ARONSON et al., 1970; GASSET et al., 1970; OLLIVIER et al., 2001; VALERO et al., 2001). A reepitelização das bordas da enxertia foi verificada através do teste negativo de fluoresceína, como sugerido por NASISSE (1985).

\section{CONCLUSÕES}

$\mathrm{O}$ adesivo de $\mathrm{n}$-butil cianoacrilato e a técnica utilizada na sua aplicação podem ser usados clinicamente para a fixação e manutenção dos botões lamelares em ceratoplastias lamelares autógenas, 
desde que seguidas as premissas para sua utilização. O n-butil cianoacrilato não é recomendado para a fixação dos enxertos conjuntivais pediculados.

\section{FONTES DE AQUISIÇÃO}

${ }^{\mathrm{a}}$ Fentanest ${ }^{\circledR}$. Cristália. Itapira, SP

${ }^{\mathrm{b}}$ Acepran $1 \%{ }^{\circledR}$. Univet S.A. São Paulo, SP

${ }^{\mathrm{c}}$ Thiopentax ${ }^{\circledR}$. Cristália. Itapira, SP

${ }^{\mathrm{d}}$ Halothano ${ }^{\circledR}$. Cristália. Itapira, SP

${ }^{\mathrm{e}}$ Anestésico ${ }^{\circledR}$. Allergan. Guarulhos, SP.

fidocaina $1 \%{ }^{\circledR}$. Cristália. Itapira, SP

${ }^{\mathrm{g} B u p i v a c a i ́ n a ~} 0,5 \%{ }^{\circledR}$. Apsen do Brasil. São Paulo, SP

${ }^{\text {h} B i p e n c i l ~}{ }^{\circledR}$. Instituto Biochimico Ltda. Rio de Janeiro, RJ.

${ }^{i}$ Vetbond ${ }^{\circledR}$. 3M do Brasil. Sumaré, SP.

${ }^{j}$ Banamine ${ }^{\circledR}$. Schering-Plough Veterinária. Rio de Janeiro, RJ.

${ }^{k}$ Epitezan ${ }^{\circledR}$. Allergan. Guarulhos, SP.

${ }^{1}$ Atropina ${ }^{\circledR}$. Allergan. Guarulhos, SP.

${ }^{\mathrm{m}}$ Dexafenicol ${ }^{\circledR}$. Allergan. Guarulhos, SP.

\section{REFERÊNCIAS BIBLIOGRÁFICAS}

ACEDO, J.T. Queratoplastia laminar. In: Queratoplastias y queratoprótesis. 2.ed. Barcelona : Edika-med, 1992. Cap.5, p.65-128.

ARONSON, S.B. et al. Toxicity of the cyanoacrylates. Archives of Ophthalmology, v.84, p.342-349, 1970.

AWE, W.C.; ROBERTS, W.; BRAUNWALD, N.S. Rapidly polymerizing adhesive as a hemostatic agent: study of tissue response and bacteriological properties. Surgery, v.54, n.2, p.322$328,1963$.

BERNIS, W.O. Ceratoplastia lamellar experimental em cães. Arquivos da Escola de Veterinária da Universidade Federal de Minas Gerais, v.32, n.3, p.305-323, 1980.

BRIGHTMAN, A.H.; McLAUGHLIN, S.A.; BROGDON, J.D. Autogenous lamellar corneal grafting in dogs. Journal of American Veterinary Medical Association, v.195, n.4, p.469-475,1989.

BROMBERG, N.M. Cyanoacrylate tissue adhesive for treatment of refractory corneal ulceration. Veterinary Ophthalmology, v.5, n.1, p.55-60, 2002

CARDARELLI, J.; BASU, P.K. Lamellar corneal transplantation in rabbits using isobutyl cyanoacrylate. Canadian Journal of Ophthalmology, v.4, p.179-182, 1969.

COOK, C.S.; PEIFFER, R.L. Complications of ocular surgery. Compendium on Continuing Education for Practing Veterinarian, v.7, n.9, p.710-720, 1985.

EIFERMAN, R.A.; SNYDER, J.W. Antibacterial effect of cyanoacrylate glue. Archives of Ophthalmology, v.101, p.958960,1983

ELLIS, R.A.; LEVINE, A.M. Experimental sutureless ocular surgery. American Journal of Ophthalmology, v.55, p.733-741, 1963.

GARRIDO, C. et al. Cola terapêutica de cianoacrilato nas perfurações corneanas. Arquivos Brasileiros de Oftalmologia, v.62, n.6, 1999. Disponível em: <http://www.abonet.com.br〉. Online. Acesso em nov. 2002.

GASSET, A.R. et al. Ocular tolerance to cyanoacrylate monomer tissue adhesive analogues. Investigative Ophthalmology, v.9, n.1, p.3-11, 1970 .

HABIN, D. Conjunctival pedicle grafts. In Practice, v.17, n.2, p.61-65, 1995 .

HAKANSON, N.; LORIMER, D.; MERIDETH, R.E. Further comments on conjunctival pedicle grafting in the treatment of corneal ulcers in the dog and cat. Journal of the American Animal Hospital Association, v.24, n.6, p.602-605, 1988.

HAKANSON, N.E.; MERIDETH, R.E. Conjunctival pedicle grafting in the treatment of corneal ulcers in the dog and cat. Journal of the American Animal Hospital Association, v.23, p.641-648, 1987.

LAUS, J.L. et al. Comparação entre ceratoplastias lamelares por enxertos autógenos, livres, de córnea e pediculados de conjuntiva. Estudo experimental no cão (Canis familiaris - LINNAEUS, 1758). Brazilian Journal of Veterinary Research and Animal Science, v.33, n.1, p.41-46, 1996 .

MARCHIONATTI, A.E. Análise comparativa entre flape de conjuntiva bulbar e transposição córneo-conjuntival no tratamento de úlcera corneana não infectada junto ao estroma médio do cão. Santa Maria, 1998. 80f. Dissertação (Mestrado em Medicina Veterinária) - Curso de Pós-graduação em Medicina Veterinária, Universidade Federal de Santa Maria.

NASSISE, M.P. Canine ulcerative keratitis. Compendium on Continuing Education for the Practicing Veterinarian, v.7, p.686-701, 1985.

OLLIVIER, F.; DELVERDIER, M.; REGNIER, A. Tolerance of the rabbit cornea to an n-butyl-ester cyanoacrylate adhesive (Vetbond ${ }^{\circledR}$ ). Veterinary Ophthalmology, v.4, n.4, p.1-6, 2001.

PAPATHEOFANIS, F.J.; BARMADA, R. The principles and applications of surgical adhesives. Surgery Annual, v.25, n.1, p.49$81,1993$.

PELISSIER, P. et al. Internal use of n-butyl 2-cyanoacrylate (Indermil) for wound closure: an experimental study. Plastic and Reconstructive Surgery, v.108, n.6, p.1661-1666, 2001.

QUINN, J. et al. A randomized trial comparing octylcyanoacrylate tissue adhesive and sutures in the management of lacerations. Journal of American Medical Association, v.277, n.19, p.15271530, 1997.

QUINN, J.V. et al. N-2-butylcyanoacrylate: risk of bacterial contamination with an appraisal of its antimicrobial effects. The Journal of Emergency Medicine, v.13, n.4, p.581-585, 1995.

RAISER, A.G. Patologia cirúrgica veterinária. Santa Maria : Universidade Federal de Santa Maria, 1995. 246p.

REFOJO, M.F. et al. Evaluation of adhesives for corneal surgery. Archives of Ophthalmology, v.80, p.645-656, 1968.

ROSENTHAL, A.R., et al. Use of a platelet-fibrinogen-thrombin mixture as a corneal adhesive: experiments with sutureless lamellar keratoplasty in the rabbit. Investigative Ophthalmology, v.14, n.11, p.872-875, 1975.

Ciência Rural, v.34, n.4, jul-ago, 2004. 
SEVERIN, G.A. Cornea - Ulcerative keratitis, general considerations. In: Veterinary ophthalmology notes. 2.ed. Colorado : College of Veterinary Medicine and Biomedical Sciences, 1976. Cap.10, p.169-185.

SKARDA, R.T. Local and regional anesthetic and analgesic techniques: dogs. In: THURMON, J.C.; TRANQUILLI, W.J.; BENSON, G.J. Lumb \& Jones' veterinary anesthesia. Philadelphia : Lippincott Williams \& Wilkins, 1996. Cap.16, p.426-447.

SLATTER, D.; HAKANSON, N. Manual de cirurgia de pequenos animais. 2.ed. São Paulo : Manole, 1998. V.2. Cap.86, p.1436-1461.
TORIUMI, D.M. et al. Use of octyl-2-cyanoacrylate for skin closure in facial plastic surgery. Plastic and Reconstructive Surgery, v.102, n.6, p.2209-2219, 1998.

VALERO, M.C.A.; HOMS, E.M.; SANZ, J.L.A. Bioadhesivos en cirurgia ocular. Archivos de la Sociedad Española de Oftalmología, n.9, 2001. Disponível em: $<$ http://www.oftalmo.com/seo>. Online. Acesso em nov. 2002 .

WILKIE, D.A.; WHITTAKER, C. Surgery of the cornea. Veterinary Clinics of North America: Small Animal Practice, v.27, n.5, p. 1067-1107, 1997. 